\title{
Tres desmesuras de los nacionalismos
}

\author{
CARLOS PEREDA \\ Instituto de Investigaciones Filosóficas \\ Universidad Nacional Autónoma de México \\ jcarlos@servidor.unam.mx
}

\begin{abstract}
RESUMEN: La primera desmesura del nacionalismo consiste en hacer primar la filiación a la nación sobre cualquier otra filiación (la familia, los amigos, la comunidad científica. .. ). La segunda desmesura se respalda en la primera: como el nacionalista no acepta identificar la nación con una comunidad construida por el nacionalismo, produce justificaciones desmesuradas echando mano de mitologías. La tercera desmesura radica en considerar las naciones como si se tratara de mónadas, con el fin de demarcar radicalmente lo interno y lo externo de cada "nosotros" nacional.
\end{abstract}

PALABRAS CLAVE: desmesura, exilio, filiación, nación, pureza

Los usos más frecuentes de la palabra "nacionalismo", como los de todas las palabras -ismos, son buenos candidatos a formular conceptos de desmesura. Los conceptos de desmesura son propios de la razón arrogante: hacen referencia a un sentir, desear, creer, valorar, actuar, cuya autoafirmación se configura por medio de una desestimación general de lo que no es ese sentir, desear, creer. . Duda: esos sentimientos, deseos, creencias. . desmesurados, ¿acaso tarde o temprano no tienden a conducirnos, a nosotros mismos y a quienes nos rodean, a alguna forma de la mala vida? Sin embargo, iintroducen en verdad los usos más frecuentes de la palabra "nacionalismo" conceptos de desmesura, e incluso, como suele afirmarse, conceptos, en algún sentido, de sectaria desmesura?

Por ejemplo, C. Ulises Moulines busca responder la segunda inquietud con una negativa. Comenzaré por examinar algunos aspectos de su propuesta.

Por supuesto, el hecho de que los nacionalismos - ¿ o algunos nacionalismos, o la mayoría de ellos, o todos? — tiendan a desmesuras —si es que éste es el caso- no implica negar que conforman tentativas importantes para satisfacer necesidades insoslayables tanto de los individuos como de las sociedades. Por eso mismo no nos debe sorprender que los nacionalismos constituyan fenómenos históricos (sociales, políticos, psicológicos, culturales) tan decisivos, del pasado y del presente. 
En su "Manifiesto nacionalista", ${ }_{1}^{1}$ Moulines desarrolla su defensa del nacionalismo a partir de una hipótesis psicológica que atañe a las emociones nacionalistas. Tiene razón, porque "nacionalismo" con frecuencia ha rimado bien, y sigue rimando bien, con otro concepto de desmesura, con "sentimentalismo": "la raíz psicológica del nacionalismo es una emoción fuerte y duradera en muchos seres humanos".

Moulines indica, de pasada, que muchos califican esta emoción de "irracional", pero que "los calificativos 'racional' o 'irracional' no sirven cuando se trata de entender los asuntos humanos". Lo que importa: la emoción nacionalista de "muchos" individuos (¿pero no de "todos"?) forma parte de una clase más general de emociones: "un fuerte sentimiento de filiación hacia un objeto que el individuo siente que lo trasciende, algo que percibe a la vez como objeto externo a sí mismo y componente fundamental de su propia identidad". ${ }^{3}$

A diferencia de Moulines, pienso que los calificativos "racional" o "irracional" ayudan, sí, cuando se trata de entender los asuntos humanos. Más todavía, creo que el contexto más básico, y más valioso, para usar esas enredadoras palabras son los asuntos humanos. Y que los otros usos de "racional" e "irracional" dependen de éstos, y hasta deben ser parasitarios suyos. $\mathrm{O}$, para evocar el vocabulario de Kant: la razón práctica prima —o al menos debe primar- sobre la razón teórica.

Considero, además, que muchas emociones poseen un contenido cognoscitivo, o, si se prefiere, son actitudes proposicionales. Si ello se acepta, se podrá defender que muchas emociones pueden ser calificadas de "racionales" o de "irracionales". Por ejemplo, mi indignación cuando se comete una injusticia es racional: una emoción, pues, que puedo defender con razones; ésta deja de serlo si yo me equivoco, pues he malentendido la situación y sólo me he imaginado esa injusticia. El miedo a contraer el sida puede ser una emoción racional y resultar muy útil en cuanto que me obliga a tomar ciertas precauciones. El miedo a la lluvia —sobre todo si se está cobijadosuele carecer de racionalidad.

Muchos sentimientos de filiación son, o tal vez mejor, provocan emociones racionales. Nos lo enseñó Ortega: "Yo soy yo y mi circunstancia, y si no la salvo a ella, no me salvo yo." Mis circunstancias (mi familia, el lugar donde trabajo...) tienden a ser "internas" a mi persona y, a la vez, "externas" a mi cuerpo, y mis sentimientos de filiación a ellas a menudo

1 "Manifiesto nacionalista (o hasta separatista, si me apuran)", Diánoia, vol. XLVI, no. 46, mayo de 2001, pp. 81-107.

2 Ibid., p. 82

3 Ibid. 
son constitutivos de lo que soy. Para seguir hablando metafóricamente: no se puede pensar el "mundo interior" y el "mundo exterior" de una persona más que a partir de complejas interrelaciones entre ellos.

Distingamos ya, entonces, entre:

(a) sentimientos de filiación, en general; $y$

(b) un sentimiento de filiación particular a cierto "objeto" real o imaginario.

En el caso que interesa en esta reflexión se trata de tener en cuenta la diferencia entre (a) y:

(b1) un sentimiento de filiación a la nación en medio de una trama de deseos, creencias, valoraciones y acciones, o "nacionalismo".

El pasaje de (a) a (b1) es, por supuesto, contingente. Estoy tentado a hacer una precisión inútil: el pasaje de (a) a (b1) es históricamente contingente, pues tal vez los nacionalismos, en el sentido más estricto de esta palabra, no sean más que algunas de las tantas apasionadas mercancías que se pusieron en circulación después de la Revolución Francesa, en el romántico siglo XIX. En todo caso, ¿por qué habría de pensarse que las naciones, tal como las piensan los nacionalismos, son las únicas maneras que poseen los animales humanos de organizarse social y políticamente?

Sin duda, se puede tener, y de hecho se han tenido y se tienen - y probablemente es inevitable tener-, sentimientos de filiación en relación con la familia, con ciertos amigos, con el barrio, con la institución en donde se trabaja (fábrica, universidad, oficina... ), con la lengua que nos enseñaron cuando nacimos, con la ciudad en que vivo, con la región en que se encuentra esa ciudad, con una religión, con sistemas políticos, con la humanidad en su conjunto, con el club de fútbol que se favorece, con cierto estilo de comidas y de bebidas... y tal vez con cualquier cosa.

No es éste el momento para discutirlo; pero sospecho que ciertos modos de cultivar ciertas filiaciones a algunas de esas circunstancias hace crecer a los animales humanos, los enriquece; como se dice, "ensanchan el apretado yo"; hasta establecen vínculos que acaso sean componentes centrales de la buena vida de las personas. Sin sus amores o sin sus amigos, o sin su lengua o su ciudad, para algunos individuos la vida deja de tener alicientes y hasta sentido. Después de todo, las filiaciones constituyen nuestras identificaciones: aquellas relaciones que contribuyen a armar la compleja trama que nos conforma.

Por eso, otros modos de cultivar filiaciones, a veces incluso las mismas, traen aparejada una vida "bruta", "pobre", "sucia", "estrecha", "infeliz" y 
hasta "corta". En la tradición suelen usarse adjetivos como ésos para referirnos a lo que solemos temer tanto: la mala vida.

La palabra "nacionalismo" se usa para defender con razones, entre otras, ciertas filiaciones, o si se prefiere, identificaciones, como las que tienen que ver con el lugar en donde nacimos, con el sistema político en el que vivimos si es que consideramos que ese sistema político es valioso porque, entre otras funciones, promueve las libertades y ensancha el ámbito de la justicia; o ciertas filiaciones a las tradiciones culturales en las que hemos crecido $s i$ es que consideramos que esas tradiciones deben permanecer vivas e incluso deben afianzarse y expandirse (digamos, en el caso de España, el humor y la tolerancia de Cervantes y, en otro orden de cosas, esa espléndida combinación que se llama "paella"; o bien, en el caso de México, la otra modernidad, la modernidad barroca que introduce una monja jerónima que nació y vivió en la Nueva España y que la cultura mexicana posterior ha reconocido - adoptado... - como mexicana: Sor Juana; o los riquísimos chiles en nogada). Estos usos de la palabra "nacionalismo" tienden a no conformar ningún concepto de desmesura. (Son simples ilustraciones de la máxima universal "es valioso defender con energía las filiaciones valiosas".)

Sin embargo, por estos usos de la palabra "nacionalismo", que seguramente pocos querrán objetar, casi nadie discute, ni sale a la calle, ni chilla, ni se da de golpes; tampoco incluye la palabra en el nombre de un partido político, ni va a la guerra, ni escribe "manifiestos nacionalistas". Para defender — si es que tiene sentido usar aquí esta palabra— a Cervantes o a los chiles en nogada, nadie improvisa pelotones de fusilamiento.

Por el contrario, los usos de la palabra "nacionalismo" construyen un concepto de desmesura, y la gente motivada por él sale a la calle y hace cosas mucho menos compartibles por otros; y esto sucede si de pronto sus usuarios sucumben a un vértigo simplificador: cuando abusivamente reducen por entero el contenido de (a) a (b1), o al menos, cuando se busca establecer una jerarquía precisa, fija y general de filiaciones en la que (b1) domina como filiación primera que debe condicionar sin medida alguna, en cualquier circunstancia, al resto de mis otras filiaciones. He aquí la desmesura (1) del nacionalismo.

Expresada esta desmesura (1) con otras palabras: el nacionalismo se convierte en ese concepto del cual precisamente se suele querer discutir cuando se discute acerca del nacionalismo, si la circunstancia "nación" es la única que importa y que, en la formulación de Ortega, agota lo que soy, provocando, entre otros efectos, emociones irracionales.

Pero ¿qué tiene de particular la circunstancia "nación" tal como la piensan los nacionalismos? Por lo pronto, por ella, llegada la situación, debo 
ofrecer mi cuerpo y mi personalísima historia psicológica; por ella, llegado el momento, hay que traicionar a la familia (a los padres, a los hijos, a mi pareja); por ella, llegada la situación, se engaña a los amigos y a las instituciones en donde trabajo; por ella, llegado el momento, se nos obliga a sacrificar ideales como la libertad y la autonomía de cada persona y, si es necesario (una "necesidad" que ni siquiera me imagino cómo se podría entender), esconder bombas en lugares públicos y hasta poner en peligro a la humanidad en su conjunto.

Sin embargo, ¿de qué hablamos cuando hablamos de ese enloquecedor por ella: de esa circunstancia tan proclive a los vértigos de lo sublime que es la nación o, más bien, la nación para los nacionalistas?

Como mucha gente, Moulines encuentra que se ha usado la palabra "nación" de manera confusa y busca aclararla con una teoría. Paul Valéry piensa que no hay nada que aclarar en esa dirección, pues no hay nada en común que constituya a las diversas naciones: "A veces la raza, a veces la lengua, a veces el territorio, a veces los recuerdos, a veces los intereses, instituyen de manera diversa la unidad nacional de una aglomeración humana organizada. La causa profunda de tal agrupamiento puede ser totalmente diferente de la causa de tal otro." 4

Para construir su teoría, Moulines desvincula el concepto de nación de un concepto político como el de Estado. Encuentro algunas dificultades. Por lo pronto, hay un grupo de naciones que son productos de la creación de los Estados, o naciones y nacionalismos estatales. Defenderé la siguiente hipótesis: muchas naciones y nacionalismos del continente americano son naciones y nacionalismos estatales. Para poner un ejemplo extremo: no hace demasiado tiempo, nada distinguía a la "nación uruguaya" de la "nación argentina": la misma configuración de la población, la misma lengua, las mismas tradiciones y costumbres, incluyendo las mismas comidas, la misma religión... Una serie de sucesos históricos —en los que intervienen de manera preponderante los intereses de la diplomacia británica- produce la creación de ambos Estados. Una vez creados como Estados independientes, comienzan historias diferentes, entre otras, historias políticas y culturales diferentes. En Uruguay se desarrolla la mitología de Artigas (primero negra, en la ciudad de Buenos Aires, que considera a Artigas un matrero sin ley, y como reacción, en Uruguay se multiplican las mitologías celestes u oficiales, rojas o socialistas, y verdes o militares); a comienzos del siglo xx, el batllismo promueve cierto tipo de socialdemocracia, y también se divulga

4 P. Valéry, CEuvres Completes, Gallimard, París, 1988, vol. II, p. 934. 
un laicismo extremo en una poderosa escuela primaria; por lo menos en la primera mitad del siglo XX, y hasta la dictadura de 1973, se vive entre fantasías varias, como la de considerarse "la Suiza de América". . ${ }^{5}$ En Argentina se promueve el culto a San Martín y, en algunos grupos, a Sarmiento; la política gira y gira en torno a esa embrollada forma de populismo - con tintes fascistas- que provoca la mitología peronista (mitología de derecha, de centro, de izquierda; incluso mitología guerrillera con los "Montoneros"); la Iglesia Católica posee un poder visible; y tampoco faltan las fantasías, como ésa de la "Argentina potencia". ${ }^{6}$ Se dirá que con elementos como éstos es arduo imaginar cómo se construyen pasiones nacionalistas generalizadas. Sin embargo, durante el siglo xx ha habido, y sigue habiendo, "hondos nacionalismos uruguayos" y "hondos nacionalismos argentinos", la mayor parte de ellos seguramente irracionales.

Por supuesto, no menos hondos e irracionales son muchos de los nacionalismos de esa inútil fragmentación suicida que se conoce como América Central.

A su vez, en el otro extremo del continente, no sería posible explicar el melting pot que es la "nación norteamericana" sin el nacionalismo norteamericano: sin sus ideales de libertad; sus insistentes emblemas; sus agresiones militares abiertas y, sobre todo, encubiertas; su CIA; su música popular; su cine, así como los logros del país para respaldar la buena vida de gran parte de sus ciudadanos.

En apariencia, al menos, hay otros tipos de naciones y de nacionalismos que no están hechos sólo de intereses, memorias relativamente recientes e ideales. En este tipo de nacionalismos se privilegian algunos de los demás factores que enumera Valéry; entre otros, la "raza". He encerrado la palabra "raza" entre duras comillas; ¿por qué?

El concepto de raza desempeñó un papel relevante en las discusiones sobre el nacionalismo a lo largo del siglo XIX.7 Después de la Segunda Guerra

5 Cfr. Juan E. Pivel Devoto y Alcira Ranieri de Pivel Devoto, Historia de la República Oriental del Uruguay (1830-1930), 2a. ed., Medina, Montevideo, 1956; Carina Perelli y Juan Rial, De mitos y memorias. La represión, el miedo y después..., Ediciones de la Banda Oriental, Montevideo, 1986; Luis Costa Bonino, La crisis del sistema político uruguayo, Fundación Cultural Universitaria, Montevideo, 1995.

${ }^{6}$ Cfr. la discusión de estos procesos y sus mitologías en Ernesto Garzón Valdés, El velo de la ilusión, Sudamericana, Buenos Aires, 2000. Si se busca aclarar el horizonte normativo a partir del cual reflexiona Garzón Valdés, consúltese su Derecho, ética y política, Centro de Estudios Constitucionales, Madrid, 1993. Desde otras perspectivas de análisis al respecto, es también útil tener en cuenta, entre otros, los trabajos publicados en Saúl Sosnowski (comp.), Represión y reconstrucción de una cultura: el caso argentino, Eudeba, Buenos Aires, 1988.

7 En la inmensa bibliografía sobre las relaciones entre los conceptos de raza y de nacionalismo, pueden consultarse: W. Bell y W. Freeman (comps.), Ethnicity and Nation-Building. Comparative, International and Historical Perspectives, Sage, Beverly Hills, 1974; D.G. Baker, 
Mundial, esta palabra se convierte en una mala palabra, y no sólo desde el punto de vista científico, sino también político y moral. Cualquiera que hoy se atreva a usar la palabra "raza" será de inmediato acusado con una palabra -ismo que con razón, creo, produce otro concepto de desmesura: racismo. De ahí la necesidad de sustituir la palabra "raza" por otra más inocua; por ejemplo, "etnia".

Moulines nos propone esa palabra para construir una teoría sobre el concepto de nación. Una sospecha: ¿acaso no se trata de aclarar un concepto confuso mediante otro más confuso y, lo que es todavía peor, con mayor capacidad de producir confusión?

El concepto de etnia es un concepto más o menos preciso si, como en las primeras generaciones de antropólogos, se construye con cierto componente biológico. Así, pertenecerían a una misma etnia, por ejemplo, aquellas y aquellos a quienes se les puede atribuir una correlación estadística significativa de ciertos rasgos anatómicos.

Sin ese componente biológico, el concepto de etnia suena más preciso, más "científico" acaso, que el de nación, y más presentable que el de raza. Pero ello es sólo una trampa si no se aclara en cada caso cómo se quiere usar la palabra "etnia".

Cuando se decide introducir en el concepto de etnia algún componente biológico, nos enfrentamos a la siguiente alternativa: o bien, la aplicación en sentido estricto de ese concepto - si es que todavía dispone de alguna aplicación - posee un rango limitadísimo (alguna que otra tribu pequeña y aislada), o bien, abrazamos la mitología biólogica, ese respaldo excelente para la producción de persecuciones, exilios y campos de concentración y su meta, la limpieza étnica.

Al respecto, no conviene olvidar nunca el entusiasmo de Hitler $-\mathrm{y}$, en algún sentido, de antecesores suyos que se hubieran sentido muy incómodos con él, como Herder, ${ }^{8}$ o no tan incómodos, como Fichte ${ }^{9}$ y, de modo más o menos implícito, de tantos otros teóricos nacionalistas- por la mitología de la naturaleza y sus razas puras y, "porque" naturales y puras, superiores.

Race, Ethnicity and Power, Routledge and Kegan Paul, Londres, 1983; A.D. Smith, The Ethnic Origins of Nations, Blackwell, Oxford, 1986; J. Kellas, The Politics of Nationalism and Ethnicity, Macmillan, Londres, 1991.

8 Para Herder, la cultura de los Estados no es "natural"; en cambio, sí lo son las de las naciones. Cfr. F.M. Barnard, Herder's Social and Political Thought: From Enlightenment to Nationalism, Clarendon, Oxford, 1965.

9 Incluso en el nivel del lenguaje, Fichte promueve políticas de "naturalización", como la de "naturalizar" el alemán "purificándolo" de latinismos. Por favor, no se pregunte por qué las palabras de raíz germana son más "puras" y "naturales" que las de raíz latina. Cfr. J.G. Fichte, Discursos a la nación alemana, Pleamar, Buenos Aires, 1964. 
¡Ay... !, la pureza es una enfermedad contagiosa: no sólo se ha hablado y se habla de razas superiores, "porque" puras. Inmediatamente han aparecido y no dejan de aparecer nacionalistas que defienden otros tipos de mitologías, esta vez, culturales (pero que, de alguna manera, buscan carecer de historia en tanto la historia implique contingencia): ${ }^{10}$ tradiciones superiores "porque" puras, lenguas superiores "porque" puras, hasta comidas superiores "porque" puras... Algo que tampoco ni siquiera imagino cómo se podría entender: esos "porqués".

Pues, ¿̇por qué, en general, lo "puro" tiene que ser necesariamente superior a lo "sincrético", a lo "mezclado"? ¿Por qué una cultura pura es mejor que una cultura híbrida?"11

En particular, por ejemplo, ¿por qué comer arroz "puro" es necesariamente superior a comer paella? ¿Por qué actuaron mal Garcilaso y Rubén Darío cuando el primero "italianizó" y el segundo "afrancesó" la poesía en castellano? ¿Fue Kant un mal filósofo porque, en lo posible para su época, estaba al tanto de lo que pasaba en otras lenguas y leía con fervor a Hume y a Rousseau? ¿Tiene sentido defender algo así como una "ciencia nacional", aislada del quehacer internacional? ¿Qué reproches me-

10 El concepto de historia que suelen cultivar los nacionalismos es muy raro. Es, por decirlo así, un concepto de una historia "no histórica": una historia providencial que nos indica qué tenemos que hacer y qué no tenemos que hacer, un Destino que nos obliga a actuar de cierta manera. ¿Cómo es esto? Sirviéndose de la conocida metáfora del espejo enterrado de Carlos Fuentes, en su libro Nación, identidad nacional y otros mitos nacionalistas (Nobel, Oviedo, 1999), Tomás Pérez Vejo expresa esta situación de manera inmejorable: "La historia, toda imagen histórica, todo discurso sobre el pasado o reconstrucción histórica, es casi siempre un intento de respuesta al problema de la identidad, a la pregunta originaria de iquiénes somos? Y, en este sentido, la nación, como sujeto histórico sería sólo la respuesta que la nueva sociedad, nacida de las convulsiones del Antiguo Régimen, da al problema de la identidad en un momento histórico concreto; la imagen que de sí misma se hace esta sociedad en un momento en que las viejas formas de identidad aparecen como obsoletas y no operativas. Cuando ser cristiano se convierte en un asunto privado y ser súbdito de un monarca en una situación reprobable, cuando la pregunta sobre quiénes somos se torna más acuciante, la historia aparece como la única capaz de dar respuestas claras y precisas y su respuesta es: somos una nación; somos la concreción histórica de un pasado que nos define y nos determina, nos hace ser lo que somos; somos españoles, o franceses, o gallegos... porque la historia no nos deja ser otra cosa; somos, en definitiva, prisioneros de un pasado al que debemos de ser fieles porque la historia nos dice que es el nuestro. El problema es que la historia, lo mismo que un espejo enterrado, devuelve siempre la imagen del que lo desentierra, no la del que se miró en él por última vez; la imagen del presente, no la del pasado. La búsqueda de la identidad se convierte así en una empresa casi metafísica, no en la búsqueda del padre, sino en la invención del padre; no en el descubrimiento del pasado, sino en la invención del pasado." (Op. cit., pp. 209-210.)

11 Quien más ha razonado para América Latina el fenómeno del hibridismo de las culturas es Néstor García Canclini, en Culturas híbridas. Estrategias para entrar y salir de la modernidad, Grijalbo, México, 1992. 
rece el multiculturalismo y su abanico variopinto de multitud de formas de vida?

Regresemos al concepto de etnia. A partir de algunas observaciones de Moulines, y de los estudios de Horowitz ${ }^{12}$ y Smith, ${ }^{13}$ podemos volver a caracterizar una etnia eliminándole sus componentes biológicos: como una población humana con raíces premodernas, identificada con un nombre, con una mitología de ancestros, que comparte memorias y tradiciones, que posee una cultura más o menos común y algunos grados de solidaridad, con Estado o sin él.

La distinción entre nacionalismos estatales (como los citados del continente americano) y nacionalismos étnicos (como los de la ex Unión Soviética o los de la ex Yugoslavia) estaría dada, ante todo, entonces, por las raíces premodernas de la cultura común (la mitología, las tradiciones...) y, por eso, podría haber en el segundo caso nacionalismos sin un Estado que los promueva.

Quizá la fuerza de muchos movimientos nacionalistas proviene, en parte, de pasar por alto algunas de estas distinciones. Por ejemplo, y por más que se aclare y se enfatice una y otra vez lo contrario, la mitología biológica tiende a no dejar de contaminar los nacionalismos, incluso los nacionalismos estatales.

Porque, insisto, qué duda cabe: ha habido y hay fuertes nacionalismos estatales - usando esa palabra en cuanto vehículo de un concepto atrozmente desmesurado y, alguna que otra vez, criminal- en Estados Unidos, en Argentina y hasta en países que cuesta una enormidad ubicar en el mapa, como Guatemala o El Salvador. Sin embargo, fuera del género satírico, nadie hablaría de una "etnia norteamericana" o de una "etnia argentina", o de esas delicias: una "etnia guatemalteca" o una "etnia salvadoreña". En efecto, cuando sucede eso que pasa todos los días, que se casa una guatemalteca con un salvadoreño, ¿se establece un matrimonio que, con pompa, merecería ser llamado "matrimonio interétnico"? ¿Ayuda a explicar algo describir los entusiasmos desaforados por ese invento de sí misma, Evita Perón, si calificamos esas extrañísimas acciones como "costumbres étnicas"? Sí, los nacionalismos estatales suelen declarar que, como su sentido de pertenencia común se basa en compartir ciertos valores y proyectos de futuro comunes, sus filiaciones nada tienen que ver con la sangre, y ni siquiera con el pasado. Pero lo que se declara ¿es toda la verdad?

Por ejemplo, el "nacionalismo norteamericano" y su sentido de excepcionalidad articulado como un "Destino manifiesto", el llamado "American Dream", declara basarse en la exclusiva defensa de valores como "todos

12 Donald Horowitz, Ethnic Groups in Conflict, University of California, Berkeley, 1985.

13 A.D. Smith, op. cit. 
los hombres y las mujeres son iguales", y en una realización de la libertad que ha hecho posible, y sigue haciendo posible, la buena vida de aquel o aquella que la busca. Sin embargo, no se necesita demasiada investigación histórica para matizar una genealogía tan límpida. Antes de la Guerra Civil, los norteamericanos hablaban de su país en plural, después de ella en singular: una sola nación. ¿Acaso el actual "nacionalismo norteamericano" y sus televisados rituales no fueron construidos en el periodo que va de la Guerra Civil a la Primera Guerra Mundial? En esos cincuenta años se buscó reunificar a los derrotados blancos del Sur con el Norte triunfador. En este sentido, la mitología de la "raza", lejos de no tener nada que ver en el actual nacionalismo norteamericano, desempeña cierto papel, aunque negativo. No es casual, pues, que después de la Guerra Civil, y coincidiendo con el surgimiento del segregacionismo en el Sur, se comience a divulgar una historia "maquillada" (bajo la descripción: los confederados y los blancos del Norte tuvieron entre sí una de las tantas "peleas de hermanos"). Como consecuencia, las organizaciones de veteranos blancos e incluso organizaciones como la Woman's Relief Corps —un grupo independiente de mujeres negras y blancas leales a la Unión-comenzaron a marginar a sus miembros negros con el objeto de eliminar su irritante presencia en la construcción de la "nación de la libertad". ${ }^{14}$

Observaciones en algún sentido — pero sólo en algún sentido- similares pueden hacerse en relación con nacionalismos estatales - alguna vez también, en tiempos mejores, con sus pretensiones de excepcionalismode países de América del Sur como Argentina y Uruguay, y también Chile, ${ }^{15}$ en donde el pasado indígena y, en algunos casos, el presente indígena se borran imaginariamente. Así, no pocos nacionalistas de tales países solían declarar (y, aunque mucho menos, todavía algunos lo suelen hacer): "somos casi europeos y, así, diferentes del resto de América Latina porque entre nosotros no hay ni hubo (?) indios".

Por supuesto, las elaboradas mitologías de los nacionalismos que enfáticamente suelen declararse como no estatales, sino étnicos, no son menos imaginarias que las vergonzantes mitologías de los nacionalismos estatales. ¿Cómo podemos explicar, sin recurrir al imaginario popular, los impulsos expansionistas serbios y su mitología de una "Serbia celestial"? ${ }^{16}$ ¿Dónde, fuera del imaginario popular, se podría aceptar la declaración de los actuales

14 Estas precisiones están basadas en Cecilia Elizabeth O’Leary, To Die For, Princeton University Press, Princeton, 1999.

15 Cfr. Sonia Montecino, "El mundo indígena en el Chile de hoy: temor y tensión de una presencia", en Manuel Antonio Garretón, Saúl Sosnowski y Bernardo Subercaseaux (comps.), Cultura, autoritarismo y redemocratización en Chile, Fondo de Cultura Económica, México, 1993.

${ }^{16}$ Cfr. Branimir Anzulovic, Heavenly Serbia: From Myth to Genocide, New York University 
coroneles griegos de descender de la sangre de Pericles y de Alejandro - una unidad sanguínea endeble- y que a la vez rechacen que sus colegas de Macedonia posean esa ilustre genealogía? ¿Dónde, fuera de una mitología religiosa, política y cultural, podríamos respaldar los tejes y manejes del "alma eslava"?

He aquí la desmesura (2) de los nacionalismos: los nacionalistas no sólo absolutizan la circunstancia "nación", sino que, como no tienen demasiado en claro qué es lo que absolutizan y no se resignan a identificar la nación con una comunidad construida, con una "comunidad imaginada" por los nacionalismos, ${ }^{17}$ tienen que producir justificaciones desmesuradas echando mano de mitologías (biológicas, políticas, religiosas, culturales, genealógicas... ).

Dos tipos de teorías sobre las naciones suelen contribuir a respaldar la desmesura (2). A estas versiones del mito de lo dado se las conoce como "primordialismo" y "perennalismo". Según el primordialismo, las naciones conforman las divisiones primordiales dadas, porque naturales, de la humanidad. Así, hay una larga tradición que ha visto a las naciones como productos del plan de Dios. Las versiones modernas de esta tradición suelen encontrarse en disciplinas - al menos a primera vista - tan poco teológicas como la sociobiología. Así, para van den Berghe, las mitologías de una descendencia compartida corresponden, en verdad, a ancestros biológicos comunes, algo explicable por la necesidad de la endogamia para forjar la identidad étnica. ${ }^{18}$

En cambio, los perennalistas contemporáneos son primordialistas sin biología. Las naciones son unidades dadas, que han existido a lo largo de la historia, pero no pertenecen al orden natural. ${ }^{19}$ La investigación empírica

Press, Nueva York, 1999. Anzulovic analiza con gran detalle tanto los actos criminales de Serbia en la década de los noventa contra Croacia, Bosnia-Herzegovina y Kosovo, como su propia ruina económica, y encuentra parte de la causa de estos actos en la mitología de una "Serbia celestial". Algunos lectores tal vez lamenten que en ningún momento Anzulovic deje de adoptar el punto de vista del nacionalismo croata.

17 La expresión "comunidad imaginada" y, en general, la propuesta de pensar los nacionalismos como comunitarismos imaginarios es razonada en el libro de Benedict Anderson, Imagined Communities: Reflexions on the Origins and Spread of Nationalism, Verso, Londres, 1991. Según Anderson, los nacionalismos son artefactos culturales propios de la modernidad, cuyo objeto, la nación, es una comunidad política imaginada como soberana, finita o delimitada, y horizontal. Para una crítica general a los comunitarismos, véase Carlos Thiebaut, Los límites de la comunidad, Centro de Estudios Constitucionales, Madrid, 1992.

18 Pierre van den Berghe, "Race and Ethnicity: A Sociobiological Perspective", Ethnic and Racial Studies, 1978, vol. I, no. 4, pp. 401-411; “Does Race Matter?”, Nations and Nationalism, vol. I, no. 3, 2000, pp. 357-368.

19 M.T. Walek-Czerneck, "Le role de la nationalité dans l'histoire de l'antiquité", Bulletin of the International Commitee of Historical Sciences, 1929, vol. 2, no. 2, pp. 305-320; Mario 
tiende a verificar que unas pocas comunidades en la Antigüedad y en la Edad Media pueden reconstruirse como "tradiciones nacionales" e incluso como "naciones" (los armenios, los judíos, los japoneses... ). Sin embargo, la rareza de tales ejemplos, como indica A.D. Smith, con dificultad la podría tomar el perennalista como prueba de que las naciones son fenómenos dados y recurrentes en la historia. De ahí la necesidad del perennalista contemporáneo de recurrir también a la mitología historiográfica, a menudo en la forma de nacionalismos retrospectivos: se impone a comunidades con identificaciones locales y preponderantemente religiosas una "identidad nacional" sobre todo política. ${ }^{20}$

Después de todo, vivir y morir por un absoluto necesita alguna justificación rotunda. Nada mejor para justificar cualquier cosa que una mitología. Por eso, indigna tanto a la política nacionalista que esos especialistas en minucias, un historiador o una historiadora (un historiador o historiadora no especulativamente nacionalistas), ${ }^{21}$ informen sobre el revés de la trama nacionalista y hablen de una nación a partir del punto de vista de la bajeza: como construcciones resultado de turbias circunstancias políticas, bélicas, económicas, pedagógicas, estéticas... De esta manera, aquello a que se hace referencia con el concepto de nación se convierte en una construcción negociada y, además, por si fuera poco, de origen poco sublime y no demasiado antiguo.

Atilio Levi, Political Power in the Ancient World, trad. al inglés J. Costello, Weidenfeld and Nicholson, Londres, 1965; Adrian Hastings, The Construction of Nationhood: Ethnicity, Religion and Nationalism, Cambridge University Press, Cambridge, 1997.

20 Anthony D. Smith, Myths and Memories of the Nation, Oxford University Press, Oxford, 1999 , p. 5.

21 La pregunta es, por supuesto: ¿qué se debe hacer para que en una cultura se desarrolle una tradición de historiadores no especulativamente nacionalistas? Para sopesar las dificultades al respecto, téngase en cuenta la siguiente observación de Paul Connerton en How Societies Remember (Cambridge University Press, Cambridge, 1989, p. 16): "the transformation of the writing of history is in large part of the work of the great German scholars, Niebuhr and Savigny, Ranke and Mommsen, Troeltsch and Meinecke, all of whom were intimately involved with the life of the political society to which they belong. They rejected any form of political universalism and in particular the principles of 1789 which claimed to establish rules of common life and of participation in the activities of the state which were valid, in principle, for all peoples; and they affirmed, in opposition to this, the value of treating law, not as socially constructed machinery, but as the embodiment and expression of a nation's continuity." ["la transformación de la forma de escribir la historia es, en gran parte, obra de los grandes especialistas alemanes, Niebuhr y Savigny, Ranke y Mommsen, Troeltsch y Meinecke, todos los cuales participaron de cerca en la vida de la sociedad política a la cual pertenecieron. Ellos rechazaron toda forma de universalismo político y, en particular, los principios de 1789 que reivindicaban tanto el establecimiento de reglas para la vida diaria, como para la participación en las actividades del Estado que fueran válidas, supuestamente, para todos los pueblos; afirmaron, en cambio, el valor de tratar la ley no como una maquinaria socialmente construida, sino como la encarnación y la expresión de la continuidad de la nación.”] 
En este sentido, creo que no exagero demasiado si observo que en muchos nacionalismos (en los nacionalismos con un alto grado de desmesura) se usa a la nación —o a la etnia, o al Estado... — como el alcohólico al alcohol.

\section{III}

Moulines piensa que sus razones en favor del nacionalismo contribuyen a respaldar un principio deontológico general, el principio del valor intrínseco de la pluralidad del ser. Este principio de pluralidad, a su vez, respaldaría con fuerza al nacionalismo: "es algo bueno, que hay que preservar, o hasta fomentar en la medida de lo posible, el que haya muchas cosas de muy diversos tipos en el universo". ${ }^{22}$

Lamentablemente, los nacionalistas suelen hacer un uso demasiado selectivo de este irreprochable principio: un "uso externo". ¿En qué consiste? Permítaseme hablar en leibniziano vago. Consideremos a cada nación, a cada etnia y a cada Estado como una mónada. Los nacionalismos tienden a defender la conveniencia de este principio pero sólo de modo externo: fuera de cada mónada. Se usa este principio como multiplicador de mónadas diferentes que, de algún modo, tienen que convivir entre sí.

He aquí la desmesura (3) del nacionalismo: se construyen abismos reales y/o imaginarios entre una mónada y las restantes con el fin de demarcar radicalmente entre lo interno y lo externo de cada "nosotros" nacional.

A partir de esa separación, en el interior de su mónada, muchos nacionalismos combaten con ardor la misma pluralidad que, con no menos ardor, dicen defender fuera de ella. De esta manera, ruidosamente se suele acatar, incluso a costa de la vida de quienes lo aceptan y de la vida de quienes se le oponen, la máxima sectaria:

Siempre es bueno más de lo mismo.

Siguiendo esta máxima, en su mónada, los nacionalistas buscan eliminar la pluralidad de rostros, de costumbres, de culturas, de lenguas, de tradiciones, de religión, de sangre. . . como, a la vez, "lo impuro" y lo "antinatural". Por eso, no es perverso conjeturar que la gran mayoría de los nacionalismos sólo defienden la pluralidad externa como instrumento para reforzar la homogeneidad interna y sus filiaciones a algún origen imaginario. Porque si lo único que importa es construir una mónada homogénea, importará construirla lo más homogénea posible: más y más de lo mismo. El nacionalista vasco

22 Moulines, op. cit., p. 102. 
busca más vascos, y, sobre todo, más de "lo vasco"; ${ }^{23}$ el nacionalista nigeriano, más nigerianos y, sobre todo, más de "lo nigeriano"; y el nacionalista chino, más chinos y, sobre todo, más de "lo chino". Mejor ni preguntar en qué consisten esas esencias: "lo vasco" o "lo nigeriano" o "lo chino", ni quién o quiénes las reconocen (quién o quiénes son expertos en esa operación sutil: descifrar el "alma nacional"). Especialmente no hay que preguntar eso, ni por lo demás nada, si estamos frente a un nacionalista vasco o nigeriano o chino, y más aún, si sospechamos que ese nacionalista vasco, nigeriano o chino está armado.

La observación anterior no es hiperbólica. Si no se admite el "uso interno" de la pluralidad y su consecuencia, el multiculturalismo propio de las culturas híbridas, no será difícil de confirmar la siguiente hipótesis psicosocial: las otras y los otros dejan de ser otras y otros reales para convertirse en otras y otros fantasmales. Las otras y los otros concretos se funden en el fantasma del Otro que ronda en los límites de la mónada. Una de las dificultades de vivir a las otras personas sólo en el régimen de lo fantasmal, y nunca en el de lo real, radica en que los fantasmas tienden a vivirse como entes amenazantes. No es casual, pues, que la defensa del nacionalismo con demasiada frecuencia retrate a los habitantes de las otras mónadas como una amenaza real o potencial a la que hay que responder o, al menos, contra la que hay que estar bien preparados.

Claro: sentirse amenazado es una correcta propedéutica para desenfundar las armas y, afuera de la muralla, empezar a hacer correr la sangre. Por eso, cuando la oposición nosotros/ellos se vuelve un absoluto que se recuerda a cada paso, la paz tiene mala fama y la guerra es inminente. ${ }^{24}$

23 Sobre "lo vasco" es inevitable leer Jon Juaristi, El bucle melancólico, Espasa-Calpe, Madrid, 1997. Para Juaristi, el nacionalismo es una "enfermedad" que transporta al nivel colectivo aquellas propiedades que posee la melancolía para los individuos: la pérdida de la infancia, de una época imaginadamente feliz. Para el nacionalista, la patria se convierte en un sustituto de la infancia. También A. Pérez-Agote, La reproducción del nacionalismo. El caso vasco, CIS/Siglo XXI, Madrid, 1986; J. Aranzadi, J. Juaristi y P. Unzueta, Auto de terminación (raza, nación y violencia en el País Vasco), Aguilar, Madrid, 1994. En relación directa con algunas observaciones de Juaristi, en parte apoyándolas, en parte criticándolas, véase las interesantes discusiones de Eduardo de Bustos, La metáfora. Ensayos transdisciplinares, Fondo de Cultura Económica/UNED, Madrid, 2000. En el capítulo IX, "La estructura cognitiva del nacionalismo: metáforas de la identidad colectiva", Bustos busca sustituir la teoría psicoanalítica, que es el trasfondo de muchas observaciones de Juaristi, por una teoría cognitivista de la metáfora. Por supuesto, cualquier reflexión en castellano acerca del nacionalismo creo que no puede dejar de tener en cuenta las agudas polémicas en su contra de Fernando Savater, desde su obra temprana Contra las patrias, Tusquets, Barcelona, 1984, hasta su reciente discusión —centrada en el caso vasco-Perdonen las molestias, Aguilar, Madrid, 2001.

${ }^{24}$ Cfr. Anthony D. Smith, "War and Ethnicity: The Role of Warfare in the Formation, Self-Images and Cohesion of Ethnic Communities", en J. Hutchinson y A.D. Smith (eds.), Nationalism. Critical Concepts in Political Science, Routledge, Londres, 2000, V, pp. 1605-1630. 
De ahí que, aunque los nacionalismos no son los únicos culpables de los crímenes políticos del siglo xx (el estalinismo es lamentablemente inolvidable), su contribución es vasta y variada. Para recordar unos cuantos acontecimientos odiosamente memorables, contribución de los nacionalismos al crimen, el siglo XX comienza con la exterminación de más o menos un millón y medio de armenios por el nacionalismo turco entre 1915 y 1917; culmina ${ }^{25}$ con esa situación absolutamente única, el Holocausto y sus, entre otros, seis millones de judíos asesinados; y, finalmente, se cierra el siglo con el duelo por los doscientos mil muertos en una región pequeñísima, Bosnia.

Por lo demás, cada uno de estos asesinatos masivos "por la patria" suele desarrollar sus propias técnicas del horror: innovadoras tecnologías de la crueldad y del asesinato. Por ejemplo, el nacionalsocialismo produce la versión definitiva del "mal radical industrializado" con su muy organizada destrucción de la vida humana en sus "campos de concentración": en sus campos de exterminio. En este sentido, el uso sistemático de las cámaras de gas como arma política es, seguramente, uno de los grandes inventos en el "progreso" del genocidio, que convierte al Holocausto en un acontecimiento tan devastador en la historia de la infamia.

El caso de la llamada por los argentinos "Guerra de las Malvinas" es una poderosa ilustración de la relación entre nacionalismo y guerra, así como de las emociones irracionales que suelen despertar los nacionalismos y las guerras nacionalistas: muchas de las víctimas de la dictadura militar —incluso en el exilio— salieron a la calle a apoyar a sus verdugos bajo el lema común "Las Malvinas son argentinas".

25 Tal vez pueda reconstruirse algo así como una causalidad simbólica del genocidio en el siglo XX. Al respecto, atiéndanse las observaciones de Herbert Hirsch en Genocide and the Politics of Memory, Chapel Hill, North Carolina, 1995, p. 75: "genocides are connected. Although the Holocaust is the most studied genocide, it was preceded by the extermination of the Armenian people in 1915-17, which served Hitler not only as a model for the processes of extermination but also as an indication of the world's lack of concern (Richard G. Hovannisian, editor, The Armenian Genocide in Perspective. [Transaction Books,] New Brunswick, N.J., 1987.) As Smith ["The Armenian Genocide: Memory, Politics and the Future", en el libro citado de Hovannisian] notes, 'Would-be perpetrators of genocide have seen what has happened with the Armenians: they know that they can commit genocide and get away with it, and through denial eventually erase any recollection of their crime. And by ignoring the Armenian Genocide, knowledge important to prevention of genocide was, for too long, lost" (p. 13). ["los genocidios están relacionados. Si bien el Holocausto es el más estudiado, fue precedido por el exterminio del pueblo armenio entre 1915 y 1917, el cual no sólo le sirvió a Hitler como modelo para sus propios procesos de exterminio, sino también como signo de la falta de interés del mundo en los genocidios. Como lo señala Smith: 'Los futuros perpetradores de genocidios han visto lo que les sucedió a los armenios: saben que pueden practicar un genocidio y salir indemnes, y negándose a aceptar que lo cometieron borran, a fin de cuentas, cualquier rastro de su crimen. Por haber ignorado el exterminio armenio, durante mucho tiempo se perdieron conocimientos de gran importancia para evitar genocidios."] 
A su vez, recientemente, al principio de la década de 1990, los serbios introdujeron el uso de "campos de violación"; en ellos fueron violadas alrededor de cincuenta mil mujeres bosnias. De esta manera, se hizo de la violación, ya no accidental sino cuidadosamente planificada, un arma política. Una enfermera describe del modo siguiente su detención en un campo de violación: "Yo era una de las mil ochocientas mujeres prisioneras en Brocko. Había seiscientas mujeres en mi cuarto. A mí me habían dado un número, el 31. Cuando ellos gritaban tu número, tenías que ir. Una mujer me contó que fue violada por cincuenta serbios." 26

Leibniz postuló una armonía preestablecida entre las mónadas. Por el contrario, la monadología nacionalista es una monadología de la exclusión y, con demasiada frecuencia, del asesinato. De ahí el deber de no dejar de tener en cuenta en nuestras reflexiones la máxima antisectaria:

No olvides que cualquier tipo de querencia posee un techo, un límite: más allá de él habita la aridez o la locura; en ambos casos, poco a poco o de súbito, comienza lo que ya no tiene sentido.

Esa máxima, aplicada al ámbito de la política, tiende a generar una prudencia generalizada, la cual incluye cautelas antinacionalistas que conducen a abrigar sospechas: a las filiaciones nacionalistas las persigue el peligro de volverse sectas cuya primera función, como la de toda secta, consiste en no dejar de excluir. Sin embargo, combatir la aridez o la locura nacionalista no es fácil: implica atacar a muchas de las Ligas de la Pureza que ha construido la razón arrogante y, así, poder renunciar al desprecio de lo que no nos continúa o no nos repite.

También con la máxima antisectaria se invita a negar esas formas de la mala vida que ordenan a las personas y a las sociedades tener un tipo de filiación excluyente, y no la opción de varios, incluyentes y combinados, y cambiantes tanto en el espacio como en el tiempo. Un efecto de esta segunda opción: nos libramos del mandamiento de escondernos en la cueva nativa y tapiar cualquier agujero que deje entrar el aire, para autointoxicarnos repitiendo el conjuro nacionalista: "Somos mexicanos, somos guadalupanos, somos mexicanos, y nada más, y nada más, y nada más; porque somos mexicanos, somos guadalupanos, somos mexicanos, y nada más, y nada más, y nada más; porque somos mexicanos, somos guadalupanos, somos mexicanos, y nada más, y nada más...", ad infinitum.

Por eso, resistir la aridez o la locura nacionalista conduce, sobre todo, a ejercitar en varios niveles —el personal, el comunitario, el institucional... -

26 Grace Halsell, “Women's Bodies a Battlefield in War for 'Greater Serbia' ”, en Washington Report on Middle East Affairs, abril-mayo de 1993, p. 9. 
la capacidad de juicio, y entre otras, las difíciles, a veces, dificilísimas virtudes de la hospitalidad que no se cansa de ensanchar el horizonte y del mestizaje que no se avergüenza de ser tal, sino que se muestra y se celebra.

\section{IV}

Las tres desmesuras anotadas de los nacionalismos conforman algo así como una trama, en muchos casos, con fuerte consistencia interna, muy característica de la razón arrogante. La desmesura (1), la absolutización de la circunstancia "nación", y el consiguiente desdén para las otras circunstancias de la buena vida —el amor a la familia, el cuidado de los amigos o de mi ciudad, el respeto a los derechos humanos, el cultivo de la justicia...es la desmesura sustantiva, la desmesura generadora de los nacionalismos. Las desmesuras (2) y (3) son adjetivas, auxiliares de ésta.

Por eso, si preguntamos qué técnicas pueden usarse para absolutizar la circunstancia "nación", dos respuestas son inmediatas. Ante todo, hay que propagar mitologías: mitologías biológicas positivas en torno a la pureza de la sangre, o negativas como las que oponen "lo blanco" a "lo negro", o a "lo bronceado" (lo indígena), o a cualquier otro color; o mitologías genealógicas y culturales que evocan ancestros y planes de vida milenarios, o muy diferentes y superiores a los otros pueblos. . . Con cualquiera de estas mitologías no será difícil establecer varias clases de demarcaciones entre lo interno y lo externo a la nación.

Si no me equivoco, en relación con las desmesuras (1), (2) y (3) pueden construirse indicadores de peligrosidad de los nacionalismos. De esta manera, podríamos comenzar a plantear estudios comparativos de los nacionalismos a partir del siguiente teorema:

El peligro de un nacionalismo crece en relación directa con el grado de desarrollo de las desmesuras (1), (2) y (3).

Así, un nacionalismo será tanto más peligroso cuanto más denigre las otras circunstancias de la buena vida; cuanto más alejadas de la verdad se encuentren sus justificaciones y menos posibilidades de crítica haya respecto de sus mitologías; cuanto más alto sea el grado de exclusión de lo externo respecto de lo interno al "nosotros". Sin duda, estas observaciones necesitan elaborarse de manera mucho más fina para llevar a cabo las investigaciones empíricas correspondientes (investigaciones históricas, sociológicas, politológicas, antropológicas, psicológicas...); pero sospecho que estamos ante un prometedor punto de partida para evaluar el grado de peligrosidad de un nacionalismo. 
Entonces, si me reconozco como parte de una cultura híbrida, no es difícil comprobar que no han surgido los nacionalismos porque en la naturaleza o en la historia se encuentren esos objetos eternos y sagrados que es necesario teorizar en general (como hacen los primordialistas y los perennalistas) y, sobre todo, idolatrar: las naciones; sino que existen las naciones porque han surgido y se han desarrollado muy diversos movimientos históricos en continua superposición -a menudo profundos movimientos sociales, políticos, económicos, religiosos, culturales...-, que de manera crítica hay que explicar tanto como evaluar de caso en caso: ${ }^{27}$ los nacionalismos.

Recibido el 4 de julio de 2001; aceptado el 19 de septiembre de 2001

27 Calhoun ataca incluso la posibilidad de una teoría general del nacionalismo, pues, según él —una opinión que comparte con autores tan diferentes como Valéry-, no hay una master variable que pueda explicar el surgimiento y el desarrollo de movimientos tan disímiles, en diferentes lugares y tiempos. Cfr. Craig J. Calhoun, Nationalism (Concepts in Social Thought Series), University of Minnesota Press, Minneápolis, 1998. 